University of South Carolina

Scholar Commons

10-1997

\title{
The Coexistence of Multiple Distribution Systems for Financial Services: The Case of Property-Liability Insurance
}

Allen N. Berger

University of South Carolina - Columbia, aberger@moore.sc.edu

J. David Cummins

Mary A. Weiss

Follow this and additional works at: https://scholarcommons.sc.edu/fin_facpub

Part of the Finance and Financial Management Commons, and the Insurance Commons

Publication Info

Published in Journal of Business, Volume 70, Issue 4, 1997, pages 515-546.

http://www.jstor.org/action/showPublication?journalCode=jbusiness

(c) 1997 The University of Chicago Press

This Article is brought to you by the Finance Department at Scholar Commons. It has been accepted for inclusion in Faculty Publications by an authorized administrator of Scholar Commons. For more information, please contact digres@mailbox.sc.edu. 


\section{J. David Cummins}

Unversity of Pennsylvania

Mary A. Weiss

Temple University

\section{The Coexistence of Multiple Distribution Systems for Financial Services: The Case of Property-Liability Insurance*}

\section{Introduction}

Economic theory predicts that in long-run competitive equilibrium the price of a good or service will equal the minimum average costs associated with the most efficient production technologyfirms that have inefficient technologies and higher average costs will not survive. The coexistence over long periods of time of alternative technologies performing the same function thus poses an interesting economic puzzle. Prominent examples are alternative distribution systems for the same or similar financial service, such as fullservice and discount brokers for performing securities trading; automatic teller machines and human tellers for distributing cash; banks, savings and loans, and credit unions for delivering

* The opinıons expressed do not necessarily reflect those of the Board of Governors or its staff The authors thank the anonymous referee, the editor (Doug Diamond), Dwight Jaffee, and the participants in the National Bureau of Economic Research Property-Liability Insurance Seminar for helpful comments. The authors acknowledge the capable research assistance of Jalal Akhavein and Joe Scalıse

(Journal of Business, 1997, vol 70, no 4)

(C) 1997 by The University of Chicago All rights reserved $0021-9398 / 97 / 7004-0003 \$ 0250$

Property-liability insurance is distributed through a direct-writer system, where agents represent one insurer, and an independentagency system, where agents represent several insurers. Independent-agency insurers have higher costs than direct writers. The market-imperfections hypothesis attributes the coexistence of the two types of insurers to impediments to competition, while the product-quality hypothesis holds that independent-agency insurers provide higher-quality services. We measure cost efficiency and profit efficiency for property-liability insurers and find strong support for the product-quality hypothesis, implying that independent-agency insurers produce higher-quality outputs and are compensated by higher revenues. 
depository services; and banks and capital markets for providing loans to businesses (Fama 1985).

This article focuses on a particularly interesting case of financialservices distribution, property-liability insurance. Property-liability insurance is distributed by two different types of firms: direct-writing insurers that distribute insurance through exclusive agents who represent only one insurer, and independent-agency insurers that distribute their product through independent agents who represent multiple insurers. These systems have long interested researchers because they have coexisted in insurance markets for many decades, even though independent-agency insurers are known to have higher costs (e.g., Joskow 1973; Cummins and VanDerhei 1979; Pauly, Kunreuther, and Kleindorfer 1986; Kim, Mayers, and Smith 1996). The purpose of this article is to analyze the reasons for the long-term coexistence of the directwriting and independent-agency distribution systems.

Two primary hypotheses have been advanced to explain the coexistence of the two systems. According to the market-imperfections hypothesis, independent-agency insurers survive while providing essentially the same services as direct-writing insurers because of market imperfections, such as price regulation (Joskow 1973; Cummins and VanDerhei 1979; Weiss 1990), slow diffusion of information in insurance markets (Berger, Kleindorfer, and Kunreuther 1989), or search costs that permit inefficient firms to survive alongside efficient firms (Dahlby and West 1986). Under the market-imperfections hypothesis, efficient firms are expected to earn supernormal risk-adjusted profits, while inefficient firms will earn risk-adjusted profits closer to normal levels.

In contrast, according to the product-quality hypothesis, the higher costs of independent-agency insurers represent expenses associated with producing higher product quality or greater service intensity, such as providing additional customer assistance with claims settlement, offering a greater variety of product choices, or reducing policyholder search costs (Pauly et al. 1986; Kim et al. 1996; Regan and Tennyson 1996). This hypothesis predicts normal risk-adjusted profits for both direct-writing and independent-agency firms.

The product-quality hypothesis implies that firms are sorted into product-quality or service-intensity market niches, with customers who prefer higher quality paying more for the product. The higher prices recelved by the higher-quality providers cover their extra production costs, allowing these firms to survive in equilibrium. This rationale is broad enough to encompass agency-theoretic explanations for the existence of alternative technologies (e.g., Mayers and Smith 1981; Kim et al. 1996). For example, principal-agent problems, such as company/buyer incentive conflicts, may be more important to some buyers or for some product variants, leading to the survival of distribution systems that deal efficiently with this type of incentive conflict. Thus, independent-agency insurers may survive because they more ef- 
fectively discipline insurers into paying legitimate claims promptly and fairly. Independent agents can credibly threaten to shift business to an alternate insurer because their contracts with insurers convey ownership of the policyholder list to the agent (i.e., the company cannot approach policyholders directly), whereas exclusive agents usually do not have this ownership right.

Because product quality in insurance is essentially unobserved, researchers have been unable to reach a consensus on whether the marketimperfections hypothesis or the product-quality hypothesis is more consistent with the observed cost data. This lack of consensus leaves open the interesting economic question of whether the market works well in minimizing product-distribution costs and leaves unresolved the issue of whether marketing costs in property-liability insurance are excessive and perhaps should receive regulatory attention. ${ }^{1}$

This article proposes a new methodology for distinguishing between the two hypotheses. Using frontier efficiency methods, we estimate both cost and profit efficiency for direct-writing and independentagency insurers. Measuring cost efficiency enables us to determine whether the cost efficiency difference between direct-writing and independent-agency insurers found by prior researchers persists under our methodology. Measuring profit efficiency helps to identify unobserved product-quality differences because customers should be willing to pay extra for higher quality. Thus, our approach allows for the possibility that one group may provide higher-quality service on average and be rewarded with higher average revenues that are reflected in profit efficiency. That is, the profit-efficiency approach allows for the possibility that some firms may incur additional costs providing superior service and be compensated for these costs through higher revenues.

A key statistic in our analysis will be the proportion of the difference in measured cost efficiency between the firms employing the two distribution systems that remains when we estimate profit efficiency. If most of the measured cost-efficiency difference remains as a profit-efficiency difference, then the market-imperfections hypothesis would be supported. In this event, the profit efficiency, which includes both cost efficiency and revenue efficiency, would reinforce the efficiency difference between the two groups. In contrast, if most of the measured costefficiency difference is eliminated when the more encompassing profit efficiency is measured, then the product-quality hypothesis would be supported. This event would be consistent with the difference in service quality being reflected in higher revenues.

By way of preview, we find data on 472 insurers over the period

1 Regulators in several states, including Calıfornı, Florıda, and Massachusetts, have argued that the high costs of automobile insurance are partly attributable to insurer inefficiency in marketing, administration, and claims settlement and that such inefficiencies should be disciplined through price regulation 
1981-90 to be fairly consistent with the product-quality hypothesis. We measure independent-agency insurers as less cost efficient on average than direct writers, but most of this measured cost-efficiency difference does not translate into a profit-efficiency difference. Indeed, after conditioning on firm characteristics, such as size and business mix, the profit-efficiency difference between the two groups of firms is quite small and not statistically significant, even though a large, significant cost-efficiency difference is still present.

The article is organized as follows. Section II summarizes some of the problems encountered in the extant empirical literature and discusses in an intuitive manner how our methodology addresses these difficulties. Section III gives the details of our methodology and model specification. Section IV discusses the measurement of inputs, outputs, and prices in property-liability insurance, and Section $V$ describes the data set. Section VI presents "simple" tests based on the average efficiency differences between direct-writing and independent-agency insurers, and Section VII provides "sophisticated" tests, which condition on other firm characteristics that may affect efficiency. Section VIII concludes.

\section{Methodological Difficulties in the Extant Literature}

Three major methodological problems have been encountered in the literature on insurance distribution systems. First, product quality is essentially unobserved. If some firms incur additional costs in providing a higher-quality product to consumers, such as extra assistance with claims settlement or greater product variety, this may be incorrectly identified as cost inefficiency unless proper controls for product quality are used. Ex ante, we might expect better service from independent agents because they can offer customers choices among the products of many insurance companies, perhaps better tailoring the insurance product to the needs of the individual customer. In addition, independent agents may be more likely to act as advocates for customers in claims-settlement disagreements than exclusive agents since independent agents are not tied to the individual insurer and can threaten to steer business elsewhere if settlements are unsatisfactory (see Kim et al. 1996). Unfortunately, control variables for insurance product quality are generally lacking in the data sets available to researchers. ${ }^{2}$

In this article, we estimate profit efficiency, which incorporates both cost and revenue efficiency and should net out most of the unobserved differences in product quality. In an efficiently functioning output mar-

2 Although prior research has consistently shown independent-agency insurers to have higher costs than direct writers, it is not obvious a prion that this should be the case For example, independent-agency insurers might benefit by sharing their agents' fixed costs with other insurers, yielding lower costs than direct writers However, any such gains may be dissipated in practice because of the difficulty of dealıng with multiple sets of forms, procedures, and computer systems by independent agents. 
ket, customers who prefer higher-quality insurance services will pay more for these services, compensating the firm with additional revenues that cover the extra costs of providing the higher-quality services.

The second major difficulty encountered in empirical studies of the product-quality versus inefficiency issue lies in the specification of the null and alternative hypotheses. Most previous studies took as the null hypothesis that all property-liability insurers have the same managerial competence or efficiency. As the alternative hypothesis, these studies allowed the predicted costs to differ only by a constant for the firms in the direct-writer and independent-agency groups (e.g., Joskow 1973; Cummins and VanDerhei 1979; Pauly et al. 1986). That 1s, the maintained hypothesis for these tests was that there were no efficiency differences within either group, with the alternative hypothesis only allowing for a crude shift in efficiency between the two groups.

Advances in the measurement of efficiency have rendered such comparisons obsolete. Frontier studies of efficiency in the insurance industry by Weiss (1990); Bughin (1993); Cummins and Weiss (1993); Fecher et al. (1993); Gardner and Grace (1993); Yuengert (1993); and Cummins and $\mathrm{Zi}$ (in press) found very significant dispersion in efficiency both within groups of insurers and between groups of insurers, clearly rejecting the maintained hypothesis of only one or two efficiency levels for all insurers.

In contrast to the prior studies comparing distribution systems in property-liability insurance, we use frontier efficiency models to allow for efficiency differences within each group of insurers. That is, each firm is allowed to have its own level of efficiency. We conduct two sets of tests. Under our simple tests, the null and alternative hypotheses are that the average efficiencies of the direct-writer and independentagency groups are equal and unequal, respectively. Under our sophisticated tests, the null and alternative hypotheses are that the efficiencies of direct-writing and independent-agency firms are equal and unequal, conditional on other factors not fully under the control of insurers in the short run. To conduct the sophisticated tests, we regress the measured cost and profit inefficiencies on variables representing firm organizational form (stock vs. mutual form of ownership), product mix, and size as well as dummy variables for the direct-writer distribution system versus the independent-agency distribution system. The sophisticated version enables us to test whether direct writers have different expected costs or profits than independent-agency firms for delivering the same output mix and quantity within the same organizational form.

The third major difficulty in the prior literature is that the cost functions specified were often ad hoc. Generally, output was measured by a single proxy variable-total losses or premiums-despite the multiproduct nature of the property-liability insurance business (e.g., Joskow 1973; Braeutigam and Pauly 1986; Pauly et al. 1986). Subsequent literature on frontıer efficiency in financial services has allowed 
for multiple products and typically used the standard translog cost function specification (e.g., Weiss 1990; Cummins and Weiss 1993). The issue of the coexistence of the two distribution systems for propertyliability insurance has not been investigated using these multiproduct, frontier efficiency techniques.

The latest efficiency studies of financial institutions have taken two further steps, which we combine in our empirical analysis. First, in addition to analyzing cost efficiency, we also analyze profit efficiency, which incorporates both cost and revenue efficiency and can help ameliorate problems of unobserved product-quality differences (see Berger, Hancock, and Humphrey 1993; Akhavein, Berger, and Humphrey 1997; Akhavein, Swamy, Taubman and Singamsetti 1997). Second, we adopt the Fourier-flexible functional form for our cost and profit function, a global approximation that has been shown to dominate the commonly specified translog form in fitting financial institution data (see McAllister and McManus 1993; Mitchell and Onvural 1996; Berger, Leusner, and Mingo 1997). Global approximations are particularly important when studying an industry like insurance, where firm scale and product mix vary widely. Local approximations, such as the translog, often perform poorly at points well away from the mean and thus are potent1ally quite inaccurate for describing much of the data.

As an additional check on the results, we also estimate efficiency from an alternative profit function that replaces the output prices in the standard profit function with output quantities, effectıvely treating output scale and mix as fixed (see Humphrey and Pulley 1997). Testing the sophisticated version of the hypotheses and estimating two different profit-function specifications helps to ensure that our conclusions are not affected by differences in firm characteristics or equation specification.

\section{Methodology and Econometric Model Specification}

Cost efficiency is defined as the minimum costs that could have been expended to produce a given output bundle divided by the actual costs expended $\left(\hat{C}^{\mathrm{min}} / \hat{C}^{\text {act }}\right)$, both adjusted to be predicted values in order to remove random error that temporarly makes costs high or low. The cost-efficiency ratio may be thought of as an estimate of the proportion of total costs or resources that are used efficiently. The ratio varies over the range $(0,1]$, with higher numbers indicating greater efficiency. Similarly, profit efficiency is the ratio of predicted actual profits to the predicted maximum potential profits that could be earned $\left(\hat{\pi}^{\mathrm{dct}} / \hat{\pi}^{\max }\right)$. Thus, the profit-efficiency ratio estimates the proportion of potential profits that are realized. Profit efficiency is also maximized at one, where predicted actual profits equal potential profits. The range of profit efficiency is $(-\infty, 1]$-there is no minimum since profits can be negative of any magnitude. 
As explained below, we report estimates of inefficiency rather than efficiency in order to facilitate comparisons between the cost and profit function results. The dollar value of cost inefficiency equals actual costs minus minimum costs and thus represents the part of actual costs that is wasted because of inefficiency. Similarly, the dollar value of profit inefficiency equals potential profits minus actual profits and thus represents the part of potential profits that is lost because of inefficiency. We will divide both measures of inefficiency by the same denominators to make them comparable below.

Our efficiency analysis utilizes the "distribution-free"' methodology introduced by Schmidt and Sickles (1984) and modified by Berger (1993). This approach avoids imposing arbitrary distributional assumptions on the data in order to separate inefficiencies from random error. Instead, we simply assume that inefficiencies are persistent or stable over time, whereas random error tends to average out over time. Other efficiency methods typically require quite restrictive distributional assumptions concerning the random errors and inefficiencies that affect costs, profits, or production. ${ }^{3}$

Formally, we refer to inputs and outputs as "netputs" and distinguish between variable and fixed netputs in our cost and profit models. The vector $y \equiv\left(y_{l}, y_{o}, y_{F}\right)$ denotes the netput vector containing $n$ variable inputs $y_{I}, m$ variable outputs $y_{O}$, and $q$ fixed netputs $y_{F}$, with the variable inputs $y_{I}$ measured negatively so that for both inputs and outputs the $y$ values give the net supply by the firm. The fixed netputs are inputs or outputs that are taken as given by the firm because they are difficult to change in the short run. The vector $p \equiv\left(p_{I}, p_{O}, p_{F}\right)$ denotes the corresponding price vector.

The cost function for insurer $i$, which takes as exogenous the input prices $p_{l}$, variable outputs $y_{O}$, and fixed netputs $y_{F}$, is specified as

$$
\ln \mathrm{VC}=\ln C\left(p_{I}, y_{O}, y_{F}\right)+\ln u_{c}+\ln e_{c}
$$

where VC is variable costs $p_{I} \cdot y_{I}$ (multiplication dot indicates inner product $) ; C\left(p_{I}, y_{o}, y_{F}\right)$ is a cost function with input prices, variable outputs, and all fixed netputs as arguments; $\ln u_{c}$ is an efficiency factor; and $\ln e_{c}$ is a random error term. This composed error, $\ln u_{c}+\ln e_{c}$, will be separated out below using the assumption that the efficiency factor $\ln u_{c}$ is stable over time, while the random error $\ln e_{c}$ tends to average out over time.

The profit function is specified very similarly to the cost function:

$$
\ln \pi=\ln \pi\left(\mathrm{p}_{l}, p_{O}, y_{F}\right)+\ln u_{\pi}+\ln e_{\pi},
$$

3 The assumption that efficiencies are relatively stable over time has been supported by earlier research (see Berger and Humphrey 1991, 1992, Berger 1993) See Berger, Hunter, and Timme (1993) for a discussion of alternative efficiency-measurement techniques 
where $\pi$ denotes profits plus a constant described below, $\ln u_{\pi}$ is an efficiency factor, and $\ln e_{\pi}$ is a random error term. The major difference between the two functions is that variable output prices $p_{O}$ in the profit function replace variable output quantities $y_{o}$ in the cost function. Under profit maximization, the firm is free to choose the variable outputs to maximize profits and failure to do so results in measured profit inefficiency. Thus, profit inefficiency includes cost inefficiency from nonoptimizing levels of inputs plus revenue inefficiency from nonoptimizing levels of outputs. ${ }^{4}$

The Fourier-flexible functional form used for the cost and profit functions includes both pure Fourier trigonometric terms (cosines and sines) and a standard translog. In forming the trigonometric terms, we adjust each of the price and output terms to lie within the interval $[0$, $2 \pi]$ before taking cosines and sines. For notational convenience, we define $z^{c}$ to be the transformed values of the cost-function arguments $\left(p_{I}, y_{O}, y_{F}\right)$ and $z^{\pi}$ to be the transformed values of the profit-function arguments $\left(p_{l}, p_{O}, y_{F}\right) .^{5}$

The Fourier-flexible form for the cost function may be written as

$$
\begin{aligned}
& \ln C\left(p_{l}, y_{0}, y_{F}\right)=\alpha+\sum_{i=1}^{n} \phi_{i} \ln p_{i}+1 / 2 \sum_{i=1}^{n} \sum_{j=1}^{n} \phi_{l j} \ln p_{i} \ln p_{\jmath} \\
& +\sum_{r=1}^{m+q} \beta_{r} \ln y_{n+r}+1 / 2 \sum_{r=1}^{m+q} \sum_{s=1}^{m+q} \beta_{r s} \ln y_{n+r} \ln y_{n+s} \\
& +\sum_{i=1}^{n} \sum_{r=1}^{m+q} \gamma_{i r} \ln p_{\imath} \ln y_{n+r}+\sum_{i=1}^{n+m+q}\left(\delta_{\imath} \cos z_{l}^{c}+\theta_{\imath} \sin z_{t}^{c}\right) \\
& +\sum_{i=1}^{n+m+q} \sum_{j=1}^{n+m+q}\left[\delta_{l j} \cos \left(z_{l}^{c}+z_{j}^{c}\right)+\theta_{l \jmath} \sin \left(z_{l}^{c}+z_{\jmath}^{c}\right)\right] \\
& +\sum_{i=1}^{n+m+q} \sum_{j=l}^{n+m+q} \sum_{k=\jmath}^{n+m+q}\left[\delta_{l j k} \cos \left(z_{l}^{c}+z_{j}^{c}+z_{k}^{c}\right)+\theta_{l \jmath k} \sin \left(z_{l}^{c}+z_{j}^{c}+z_{k}^{c}\right)\right] \\
& +\ln u_{c}+\ln e_{c} \text {. }
\end{aligned}
$$

4 Because profits may be nonpositive and logs can only be taken of positive numbers, we include in $\pi$ the value one plus the absolute value of the largest negative profits in the sample That is, the dependent variable for firm $k$ at time $t$ is $\ln \pi_{k t} \equiv \ln \left(\right.$ PROFIT $_{k t}+1$ $+\left(\right.$ PROFIT $\left._{\text {min }} \mid\right)$, where PROFIT ${ }_{k t} 1$ measured profits and min indicates the sample min1mum, which is negative This modification is made for all observations.

5. We cut $10 \%$ off of each end of the $[0,2 \pi]$ interval to reduce approximation problems near the endpoints Thus, for each argument of the cost or profit function $\ln x$, we form the adjusted variable $z \equiv .2 \pi-\mu a+\mu \ln x$, where $[a, b]$ is the range of $\ln x$ and $\mu \equiv$ (9 $2 \pi-.12 \pi) /(b-a)$ 
Thus, each of the input prices, variable output quantities, and fixed netput quantities appears in the translog and Fourier functions, up to the second order in the translog and third order in the Fourier (time and firm subscripts are suppressed for notational convenience). The standard symmetry restrictions apply to the translog portion of the function $\left(\phi_{l j}=\phi_{j l}, \beta_{r s}=\beta_{s r}\right)$. The profit function has exactly the same functional form and the same number of terms as the cost function; that is, it includes the standard translog terms and the same number and type of trigonometric terms. The only difference is that output prices $\left(p_{O}\right)$ appear in the standard profit function in place of the output quantities $\left(y_{0}\right)$ that appear in the cost function (with the appropriate change in the $z$ terms as well). The alternative profit function is exactly the same as the cost function, the only difference being the dependent variable. Actual profits are used as the dependent variable in both the standard and alternative profit functions.

We use the same functional form for the cost and profit functions so that any differences we observe in measured cost and profit efficiencies are due to the efficiency concept (i.e., cost efficiency vs. profit efficiency) and not to the choice of functional form. Using the same functional form enables us to avoid confounding inefficiency differences with specification differences. The alternative profit function and the cost function not only have the same functional form but also have exactly the same right-hand side variables as well.

The models are estimated using a pooled cross-section, time-series sample of 472 insurers with continuously available data over the 10year period 1981-90. Inefficiency is estimated for each firm by averaging its residuals over the 10 -year period, truncating the distribution of average residuals across firms, and then computing efficiency relative to the firms with the best average residuals (lowest for costs, highest for profits). Specifically, under the distribution-free method, the costfunction error term for insurer $k$ at time $t\left(\ln u_{c k t}+\ln e_{c k t}\right)$ is treated as a composite error term, and the average of the 10 residuals for each insurer $k$ is calculated. This average residual, denoted by $\ln \hat{u}_{c k}$, is an estimate of $\ln u_{c k}$, given that the random errors $\ln e_{c k t}$ tend to cancel each other out in the averaging. ${ }^{6}$ The estimated cost efficiency for firm $k, \mathrm{EFF}_{c k}$, is then calculated as

$$
\mathrm{EFF}_{c k}=\exp \left(\ln \hat{u}_{c}^{\mathrm{m} \ln }-\ln \hat{u}_{c k}\right)
$$

6 Because the averaging procedure is 1 mperfect, the average residuals still contain some error from the $\ln e_{c k s}$ not fully canceling out over the 10-year period as well as standard estimation error This error is likely to be largest for insurers near the extremes of the in $\hat{u}_{c k}$ 's, which may have had persistently "lucky" or "unlucky" random errors that did not fully average out For this reason, we compute truncated measures as in Berger (1993), setting the top and bottom $5 \%$ of the $\ln \hat{u}_{c k}$ 's to the 5 th and 95 th percentiles, respectively, of their distributions 
where $\ln \hat{u}_{c}^{\mathrm{min}}$ is the minimum $\ln \hat{u}_{c k}$ and acts as an "anchor" so that the firm with the lowest average cost function residual is measured as being $100 \%$ efficient.

Profit efficiency is computed similarly to cost efficiency. ${ }^{7}$ Our measured profit efficiency ratio, $\mathrm{EFF}_{\pi k}$, is an estimate of the ratio of predicted profits for insurer $k$ to the predicted profits for the most efficient insurer, both evaluated at the mean levels for the profit function regressors for firm $k^{8}$

\section{Definition and Measurement of Outputs and Inputs}

This section briefly discusses several measurement issues in constructing the data set. We first describe the process for choosing which services to measure as outputs in property-liability insurance. We then show how we measure the output and input quantities and prices used in the cost and profit functions. More detailed information is available from the authors.

\section{Definition of Insurance Output}

Insurers are analogous to other financial firms in that their outputs consist primarily of services, many of which are intangible. Three principal approaches have been used to define outputs in the financial services sector: the asset or intermediation approach, the user-cost approach, and the value-added approach (see Berger and Humphrey 1992). We adopt a modified version of the value-added approach here, which

7. We use total profits in constructing the dependent variable for the profit function rather than variable profits, which would be analogous to variable costs If output prices and quantities were measured perfectly, the dependent variable $\pi$ would be appropriately measured using variable profits However, it is important for studying the question at hand to allow for the possibility that output prices and quantities may not be measured well, $1 \mathrm{e}$, that there may be important product-quality differences that are not incorporated in these measures. Thus, we allow for the possibility that firms using one of the distribution systems may be more efficient on average if they provide higher (unmeasured) product quality on average and receive higher revenues reflectıng this

8 A complicatıng factor is that actual profits are not multıplicative in the efficiency factor $u_{\pi}$ because of the addition of an extra constant (one plus the absolute value of the largest negative profits) before logging the profits The efficiency ratio for firm $k$ will therefore depend somewhat on the level of the regressors in the profit function, so we evaluate efficiency at the mean values of the regressors for the firm. Formally, for insurer $k$, we compute the average predicted value of the dependent variable $\ln \pi_{k}^{\text {red }}$ as the inner product of the regression coefficients and the mean regressors for firm $k$ plus the average residual $\ln \hat{u}_{\pi k}$ (truncated at the 5th and 95th percentiles as above). The value that the dependent variable would take for a fully efficient firm facıng firm $k$ 's mean regressors is $\ln \pi_{k}^{\max }=\ln \pi_{k}^{\text {pred }}+\ln \hat{u}_{\pi}^{\max }-\ln \hat{u}_{\pi k}$, where $\ln \hat{u}_{\pi}^{\max }$ is the maximum value of the $\ln \hat{u}_{\pi k}$ distribution (after truncation). Undoing the logs and subtracting the constant (1 + |PROFIT $\left._{\text {min }} \mid\right)$ from both predicted and maximum profits gives PROFIT Pred $_{k}=\exp \left(\ln \pi_{k}^{\text {pred }}\right)-(1$ $+\mid$ PROFIT $\left._{\min } \mid\right)$ and similarly for PROFIT ${ }_{k}^{\max }$ The profit-efficiency ratio is thus given by PROFIT ${ }_{k}^{\text {pred }} /$ PROFIT $_{k}^{\text {max }}$ 
counts as important outputs those that have significant value added, as judged using operating cost allocations.

Property-liability insurers provide three principal services:

1. Risk pooling and risk bearing. Insurance provides a mechanism for consumers and businesses exposed to property-liability losses to engage in risk reduction through pooling. The actuarial, underwriting, and related expenses incurred in pooling are major components of value added in the industry. Insurers also add value by holding equity capital to bear the residual risk of the pool.

2. Real services relating to insured losses. Insurers provide a variety of real services for policyholders, including risk surveys, coverage design, loss-prevention services, and loss-settlement services. By contracting with insurers to provide these services, policyholders can take advantage of insurers' extensive experience and specialized expertise to reduce costs associated with insurable risks.

3. Intermediation. Insurers collect premiums in advance of loss payments and hold the funds in reserves until claims are paid, similar to corporate debt. Policyholders receive a discount in their premiums to compensate for the opportunity cost of the funds held by the insurer, analogous to interest payments on corporate debt. The borrowed funds are invested primarily in marketable securities.

Obtaining precise information on value added in property-liability insurance is difficult, but some rough estimates are available to help identify outputs. In 1994 , about $32.0 \%$ of total industry operating expenses (expenses other than paid and incurred losses) were for losssettlement services, the primary real service provided by the industry. About $65.8 \%$ of operating costs were accounted for by marketing and administrative costs. Some of these costs are attributable to real services but the majority, such as actuarial, underwritıng, and administrative costs, are attributable to the risk pooling/bearing function. The remaining $2.2 \%$ of operating expenses were absorbed by the intermediation function. The small percentage of operating costs attributable to intermediation reflects the fact that property-liability insurers invest almost exclusively in marketable securities.

A strict application of the value-added approach would identify risk pooling/bearing and real services as important outputs and intermediation as an unimportant output. However, in view of the amount of assets controlled by insurers (about $\$ 705$ billion in 1994) and the importance of investment income as a source of revenue for the industry, we elected to retain the intermediation function in defining industry output. This is particularly important in estimating the profit function in view of the fact that insurers rely on investment income to cover the premium discount for the use of policyholder funds. A small amount of inefficiency in investing these funds could easily wipe out all profits. 


\section{Measurement of Output Quantities}

Unfortunately, transactions flow data to measure insurance outputs, such as the number of applications processed, the number of policies issued and renewed, the number of claims settled, and so forth, are not available. However, a satisfactory proxy for the amount of risk pooling/ bearing and real insurance services provided is the present value of real losses incurred. Losses incurred are defined as the value of claims that are expected to be paid as the result of providing insurance coverage during a particular period of time. ${ }^{9}$ Because the objective of risk pooling/bearing is to collect funds from the policyholder pool and equity providers and redistribute these funds to those who incur losses, proxying output by the amount of losses incurred seems quite appropriate.

There are two drawbacks to the use of discounted real losses as the metric for insurance output, both of which are addressed by our use of the profit function. First, although services are likely to be highly correlated with real losses for both direct writers and independentagency firms, measured losses will not capture any systematic differences between direct writers and independent-agency insurers in the levels of service intensity per dollar of loss. Such differences in intensity levels, such as additional help to customers in loss settlement or policy choice, likely cannot be well measured by losses or by any other observable variables. Use of the profit function may help ameliorate this problem, since the unmeasured extra service will create revenues that tend to offset the costs of providing the service.

The second drawback of using losses incurred to measure insurance output is that its use ignores the output qualities of loss control and risk management. An insurer that is very successful in its underwriting and loss-prevention practices will incur fewer losses for the same amount of premiums written but will be measured as having less output. Similarly, a firm that is relatively successful at managing its risks will

9 The measure of losses we use is calendar year (CY) losses incurred The CY losses incurred include the companies' current estimates (as of the end of year $t$ ) of losses incurred due to coverage provided in year $t, 1 \mathrm{e}$, accident year (AY) losses incurred, as well as the loss reserve adjustment (LRA), which represents the addition to (or subtraction from) AY losses in year $t$ due to revisions in reserves for prior years' losses We include the LRA in our loss measure because excluding it would result in our using a preliminary measure of output rather than actual output We include the LRA in the year in which the adjustment is made rather than the year of origin of the policies giving rise to the adjustment because the LRA reflects new information on the frequency and/or severity of claims that becomes avallable in year $t$ and also reflects services such as legal-defense and loss-adjustment services provided in year $t$ rather than the year of origin As a practical matter, the year to which the LRA is assigned is likely to have minimal effects in any case, given our use of the distribution-free approach to measuring efficiency Under this approach, the estimated inefficiencies are averaged across the sample period for each firm so that any errors resulting from the misassignment of output within the sample period tend to average out 
earn higher risk-adjusted average profits for it owners. Fortunately, our use of the profit function at least partially ameliorates these measurement problems as well-insurers that have higher-quality underwriting and loss prevention or superior risk management will have higher average profits and higher measured profit efficiency, all else equal. Such differences are not generally reflected in cost efficiency.

Because risks, payout patterns, and service intensity vary by line of business, we disaggregate losses into four subcategories: short-tail personal lines, short-tail commercial lines, long-tail personal lines, and long-tail commercial lines. ${ }^{10}$ Because insurers report their losses incurred at undiscounted values, we discount the losses to present value using estimated industry-wide payout patterns. ${ }^{11}$ The discounted losses are then expressed in real 1982 dollars by deflating by the consumer price index (CPI). ${ }^{12}$

In addition to our four insurance outputs (long- and short-tail personal and commercial lines), we also account for the intermediation function of borrowing from policyholders and investing the funds in marketable securities. The intermediation output is measured by the mean of total real invested assets for the year, with the CPI (base year is 1982) used as the deflator.

\section{Measurement of Output Prices}

The conventional measure of the price of insurance in prior research is the markup of premiums over losses; that is, the ratio of premiums to losses minus one (e.g., Pauly et al. 1986). However, the premium represents the present value of expected losses, expenses, and profits, whereas losses are reported as undiscounted values. To measure insurance output prices accurately, it is necessary to separate the price of insurance from the cost of funds borrowed from policyholders by comparing premiums with the present value of losses (see, e.g., Winter

10. "Short-tall" and "long-tall" refer to the length of time between policy inception date and when the bulk of the loss payments have been made. In short-ta1l lines such as auto collision, the lag is usually less than 2 years, while for long-tail lines such as commercial liability some losses may remain unpaid for 10 or 15 years

11 The discount rates are based on the U.S Treasury yield curves reported by Coleman, Fisher, and Ibbotson (1989) and updated through 1900 using data from other sources Payout patterns are estımated from data reported in Best's Aggregates and Averages (A M Best Co, vanous years) We estimate the payout proportions using the method prescribed by the Internal Revenue Service for obtaining the present value of losses for tax purposes

12 Losses incurred include an estımate of expected inflation between the reporting date (year $t$ ) and the projected claim settlement dates Thus, discounting at Treasury yields implicitly expresses losses for year $t$ at the price level applicable to that year, assuming that Treasury yields include a component for expected inflation. Deflating by the CPI then expresses the discounted losses for the various years of the sample period in real terms For a discussion of the rationale for this procedure, see Kraus and Ross (1982) 
1994). Thus, we measure the prices of the four insurance outputs as

$$
p_{\imath}=\frac{\operatorname{PREM}_{t}-\operatorname{PV}\left(L_{\imath}\right)}{\operatorname{PV}\left(L_{1}\right)},
$$

where $\mathrm{PREM}_{t}$ is the real premium for output category $i, L_{l}$ measures the real losses for output category $i$, and PV is the present value operator. Thus, the price is the net real cost to the policyholders of having the present value of a dollar of real losses redistributed through the insurance company.

The price of the intermediation output is the expected rate of return on assets, defined as the weighted average of our estimates of the expected returns on stocks and bonds. The weights are the proportions of each insurer's investment portfolio held in stocks and bonds. ${ }^{13}$ Expected investment income is the sum of the expected income on stocks and debt instruments. The expected rate of return on stocks for any given year is estimated as the average 90-day Treasury-bill yield for the year plus the expected equity risk premium for common stock with a beta coefficient of 1.0, assuming that insurers hold stock portfolios of average risk. ${ }^{14}$ Using this approach smooths out fluctuations due to capital gains and reflects the fact that investment decisions are based on ex ante rather than ex post returns. ${ }^{15}$ For debt instruments, actual income was used as a proxy for expected income because variability

13 Stocks, bonds, and short-term debt instruments such as Treasury bills constitute about $96 \%$ of insurer investment portfolios In computing the weights, other investments were assigned to the most appropriate category, e g , mortgages were assigned to the bond category, real estate to the stock category, etc

14. The assumption that insurer stock portfolıs have average systematic risk is reasonable because insurers tend to hold broadly diversified portfolıos (Badrinath, Kale, and Ryan 1996), so actual betas are not likely to be far from our assumed value of 10 This is partly due to the generally conservative investment approach taken by most insurers and partly due to regulation Many states restrict insurers from investıng more than a specified percentage of their assets in any one stock and additionally restrict insurers from holding more than a specified fraction of any firm's stock Some states also limit the percentage of an insurer's total assets that can be invested in stocks During our sample period, propertyliability insurers invested between $13 \%$ and $19 \%$ of their assets in stocks so that our assumption that beta $=1$ has only a small effect on the total measured price of the intermediation output. The majority of their portfolios in all years was invested in investment-grade bonds. The highly publicized insurance insolvencies related to junk bonds and real estate involved life insurers, rather than property-liability insurers

15 By using market-based returns rather than actual returns in constructing the price, we allow for the possibility of some firms being more efficient in investing. Insurers with consistently superior investment performance relative to other insurers will be appropriately measured as more profit efficient, all else equal. Insurers that take more risk also are expected to have higher investment returns than insurers with more conservative portfolios However, in a competitive market, riskıer insurers command lower prices in insurance markets so that lower premium revenues would at least partly offset the higher investment returns. 
in debt returns across companies primarily reflects differences in the maturity structure of bond portfolios, not inefficiency. ${ }^{16}$

\section{Defining and Measuring Input Quantities and Prices}

Insurance inputs can be classified into four groups: labor, business services, debt capital (including policyholder funds), and equity capital. We treat labor as a variable input and measure its price by a weighted average wage index derived from U.S. Department of Labor data on average weekly employee wages by state for Standard Industrial Classification (SIC) Class 6331: Fire, Marine, and Casualty Insurers. It is important to consider interstate differences in wages because the insurers in our sample differ significantly in the geographic distribution of their business. We take a weighted average of weekly wages by state, using the proportions of an insurer's total premiums written in each state as weights (insurance employment by state is not available). The resulting series is indexed in real terms to 1982 using the CPI. The business services input category is dominated by outside business services, such as loss-settlement services from lawyers and loss-settlement firms. ${ }^{17}$ The input price index for business services is calculated similarly to the labor price index using SIC 7399, business services, by state.

The final two inputs, which reflect the funding sources of the property-liability insurance industry, are treated as fixed netputs in our analysis. The debt capital of insurers consists primarily of funds borrowed from policyholders and is measured as the sum of loss reserves and unearned premium reserves. Loss reserves represent the company's obligations for unpaid losses, and unearned premium reserves represent premiums held for coverage not yet provided. Equity capital is an input for the risk pooling/bearing function because it provides assurance that the company will pay claims if they are larger than expected. Debt

16. We also conducted tests using an alternative measure of the intermediation output price that reflects an ex ante bond return concept Specifically, we computed the portfolio weights for the insurers in the sample for three categories of investments: $(a)$ Bonds with maturity greater than 1 year, $(b)$ debt instruments with maturity less than 1 year, and (c) stocks. Assets not falling into one of the three categories were assigned to the most appropriate of the three categories For the ex ante return on bonds in category $a$, we used the yield on 5-year Treasury bonds, for category $b$, we used the yield on 6-month Treasury bills; and for category $c$, we used the 90-day Treasury-bill rate plus the beta $=1$ CAPM risk premium, as explained above. The yields were weighted by the proportions of the three categones of assets in the portfolios of each insurer, and the weighted average yield was used as the alternative measure of the price of the intermediation output The results using this alternative intermediation output price measure were qualitatively the same as those reported in the article

17 The costs of physical capital (mainly rental expenses and computers) are small relative to the other inputs, so we do not include a separate price for this type of input. 
and equity capital are expressed in 1982 dollars by deflating by the CPI.

It might be argued that our two fixed netputs, debt capital and equity capital, are fixed only in the short run and may vary somewhat over our 10-year sample period in reaction to relative price changes. However, we prefer to hold these measures statistically fixed because the current distribution of insurer size evolved over a period of many decades. That is, the smallest firms or even the average firms could not accumulate nearly as much policyholder debt capital or equity capital as the largest firms in a single decade. When we tried treating the capital variables instead as variable inputs, the profit-efficiency rankings were completely dominated by the largest firms, which had the highest profits for a given set of prices by virtue of their cumulative size. Thus, for the remainder of the analysis, we treat the capital inputs as fixed.

To summarize, we specify five variable outputs-real discounted losses incurred on four types of insurance output (short- and long-tailed for both commercial and personal lines) and real invested assets. We also specify two variable inputs, labor and business services, and two fixed inputs, policyholder-supplied debt capital and financial equity capital. These nine netputs-which are included in either quantity or price form in the cost- and profit-efficiency equations - should reasonably represent the conditions facing insurers as they attempt to minimize costs and maximize profits.

\section{The Data}

The primary source of data for this study is the A. M. Best Company tapes, which are based on annual regulatory statements filed with state insurance commissioners. The distribution-free approach requires a panel of firms with data continuously available over a sufficiently long sample period to average out most of the random error. We chose the 10-year period 1981-90, the longest period for which all of the data were available to us. The decision-making units in the insurance industry consist of groups of affiliated insurers under common ownership as well as individual, unaffiliated insurers. Our sample consists of all groups and unaffiliated insurers for which meaningful data were available over the sample period, a total of 472 insurers. These firms accounted for $88.9 \%$ of industry assets in 1985 , the midpoint of the sample period, so that our results may be considered reasonably representative of the entire industry.

A few of the firms had incomplete information or mixed information on their distribution systems. Of the 472 insurers used in the efficiency estimations, 393 have clear distribution-system affiliations-114 direct writers and 279 independent-agency firms. Thus, while we include the 
entire 472 firms in the efficiency estimation, we compare the average efficiencies of only 393 of them in order to make the clearest distinction for answering the question of why both distribution techniques persist in the market. Summary statistics on the variables used in estimating the models are presented in table 1.

\section{Simple Hypothesis Tests Based on Average Inefficiencies}

We estimated the cost and profit models using ordinary least squares over the full 10-year period $1981-90 .{ }^{18}$ The resulting inefficiency estimates are summarized in table 2 . The inefficiency ratios are categorized by distribution system and by insurer size quartile (smallest quartile $=$ SIZE 1), with insurers ranked by total insurance output, which is the sum of the four insurance outputs (the total present value of real losses).

The "Cost Inefficiency/Actual Costs" panel of the table provides estimates of cost inefficiency divided by actual predicted costs. These are estimates of the proportion of actual costs that are lost due to inefficiency. The results presented in table 2 are weighted averages, with weights proportional to predicted costs. The weighting allows us to view the averages as estimates of the proportions of total sample costs that are lost. ${ }^{19}$ We report these estimates of cost inefficiency in part to determine whether the results of prior studies of insurance distribution systems, which focused exclusively on costs rather than profits, are robust to the choice of functional form and estimation methodology. The cost-inefficiency estimates are also important for evaluating our hypotheses to see what proportion of cost inefficiency remains as profit inefficiency. If the prior results were due to methodological flaws and, in fact, direct writers and independent-agency insurers were equally cost efficient on average, then there would be no economic puzzle of the long-term coexistence of two systems with different

18 There are 4,720 total observations used in the efficiency estımations (472 firms $\times$ 10 years) The recommended number of parameters to include in Fourier-flexible specifications $154,720^{2 / 3}$, about 281 The full model in eq. (3) with a translog plus all first-, second-, and third-order Founer terms had 492 parameters. To reduce this number while maintaining symmetric treatment of all the outputs, we dropped all the third-order trigonometric terms in which the same $z$ terms appeared more than once $(1 \mathrm{e}$, the terms in the sum in which $\imath=\jmath, l=k$, or $\jmath=k$ ). For reasons of collineanty, we also dropped the second-order Fourier terms in which both terms represented the variable input prices. The remaining specifications had 324 parameters, reasonably close to the recommended number We note that $F$-tests of the null hypothesis that all the Fourier coefficients were zero always rejected the null, confirming that the Fourier-flexıble functional form fits the data better than the more commonly specified translog form The cost- and profit-function estimates are avalable from the authors

19 We also conducted tests based on unweighted averages, which give similar results and are avalable from the authors 
TABLE 1

Variables Used in the Cost and Profit Functions

\begin{tabular}{|c|c|c|c|c|c|c|}
\hline \multirow[b]{2}{*}{ Variable } & \multirow[b]{2}{*}{ Definition } & \multicolumn{5}{|c|}{ Sample Means in 1990 by Insurer Type } \\
\hline & & $\begin{array}{l}\text { Direct } \\
\text { Wniters }\end{array}$ & $\begin{array}{l}\text { Independent } \\
\text { Agency }\end{array}$ & $\begin{array}{c}\text { Mixed } \\
\text { Distribution } \\
\text { System }\end{array}$ & $\begin{array}{c}\text { Missing } \\
\text { Distribution } \\
\text { System }\end{array}$ & Total \\
\hline$N$ & Number of firms & 114 & 279 & 26 & 53 & 472 \\
\hline$S$ & $\%$ stock & 281 & $502 * * *$ & 846 & 415 & 45.8 \\
\hline VC & Vanable costs & 241.03 & 15269 & 5570 & 3296 & 155.24 \\
\hline$\pi$ & Profits & 32.64 & 1460 & 11.57 & 483 & 17.70 \\
\hline P1 & Price of labor input & 1104 & $1111 * *$ & 1238 & 1253 & 113 \\
\hline $\mathrm{P} 2$ & Price of materials input & 1.038 & 1044 & 1100 & 1129 & 1.06 \\
\hline P3 & Price of short-tall personal lines output & .576 & $668 * * *$ & .564 & .573 & 629 \\
\hline P4 & Price of short-tall commercial lines output & 663 & $938 * * *$ & .685 & 740 & 836 \\
\hline P5 & Price of long-tall personal lines output & .504 & $704 * * *$ & 491 & 501 & 621 \\
\hline P6 & Price of long-tall commercial lines output & 1041 & $1110^{* *}$ & 921 & 937 & 1.064 \\
\hline P7 & Price for real investment output & 100 & $.104 * *$ & 103 & 107 & .103 \\
\hline Y3 & Short-tall personal lines output present value of real losses & 64.91 & $1522 *$ & 1008 & 361 & 2564 \\
\hline Y4 & Short-tall commercial lines output. present value of real losses & 32.59 & 2215 & 23.48 & 14.00 & 2383 \\
\hline Y5 & Long-tall personal lines output present value of real losses & 13891 & $4039^{*}$ & 7.85 & 705 & 5865 \\
\hline Y6 & Long-tal commercial lines output. present value of real losses & 3752 & 49.91 & 1521 & 16.12 & 4121 \\
\hline Y7 & Output volume for real invested assets & 73410 & 41518 & 21267 & 13855 & 449.99 \\
\hline Y8 & Policy holders' real debt capital input & 54247 & 36242 & 16812 & 10868 & 366.71 \\
\hline Y9 & Volume of real equity capital input & 28090 & 14478 & 7969 & 6294 & 164.88 \\
\hline
\end{tabular}

Note -Quantities are in millions of real 1982 dollars

* Difference between direct-Wrier mean and independent-agency mean is statistically significant at the $10 \%$ level

** Difference between direct-writer mean and independent-agency mean is statistically significant at the 5\% level

*** Difference between direct-writer mean and independent-agency mean is statıstically significant at the $1 \%$ leve 


\begin{tabular}{|c|c|c|c|c|c|c|c|c|c|c|c|c|}
\hline & \multicolumn{3}{|c|}{ Cost Inefficiency/Actual Costs } & \multicolumn{3}{|c|}{$\begin{array}{l}\text { Cost Inefficiency/ } \\
\text { Potentral Profits }\end{array}$} & \multicolumn{3}{|c|}{$\begin{array}{l}\text { Standard Profit Function } \\
\text { Profit Inefficiency/ } \\
\text { Potential Profits }\end{array}$} & \multicolumn{3}{|c|}{$\begin{array}{l}\text { Alternative Profit Function } \\
\text { Profit Inefficiency/ } \\
\text { Potentıal Profits }\end{array}$} \\
\hline & $\begin{array}{c}\text { Direct } \\
\text { Writers }\end{array}$ & $\begin{array}{c}\text { Independent } \\
\text { Agency }\end{array}$ & $t$-Test & $\begin{array}{c}\text { Direct } \\
\text { Writers }\end{array}$ & $\begin{array}{l}\text { Independent } \\
\text { Agency }\end{array}$ & $t$-Test & $\begin{array}{c}\text { Direct } \\
\text { Writers }\end{array}$ & $\begin{array}{l}\text { Independent } \\
\text { Agency }\end{array}$ & $t$-Test & $\begin{array}{l}\text { Direct } \\
\text { Writers }\end{array}$ & $\begin{array}{l}\text { Independent } \\
\text { Agency }\end{array}$ & $t$-Test \\
\hline SIZE 1 & $\begin{array}{l}432 \\
(17)\end{array}$ & $\begin{array}{l}410 \\
(80)\end{array}$ & -433 & $\begin{array}{r}095 \\
(17)\end{array}$ & $\begin{array}{r}099 \\
(80)\end{array}$ & 220 & $\begin{array}{l}979 \\
(17)\end{array}$ & $\begin{array}{l}991 \\
(80)\end{array}$ & 538 & $\begin{array}{l}914 \\
(17)\end{array}$ & $\begin{array}{l}909 \\
(80)\end{array}$ & -078 \\
\hline SIZE 2 & $\begin{array}{l}332 \\
(24)\end{array}$ & $\begin{array}{l}438 \\
(73)\end{array}$ & 2.448 & $\begin{array}{l}.180 \\
(24)\end{array}$ & $\begin{array}{r}232 \\
(73)\end{array}$ & 1758 & $\begin{array}{l}903 \\
(24)\end{array}$ & $\begin{array}{l}927 \\
(73)\end{array}$ & .819 & $\begin{array}{l}847 \\
(24)\end{array}$ & $\begin{array}{l}893 \\
(73)\end{array}$ & 700 \\
\hline SIZE 3 & $\begin{array}{l}315 \\
(30)\end{array}$ & $\begin{array}{l}462 \\
(64)\end{array}$ & 4406 & $\begin{array}{r}509 \\
(30)\end{array}$ & $\begin{array}{l}.636 \\
(64)\end{array}$ & 1270 & $\begin{array}{l}644 \\
(30)\end{array}$ & $\begin{array}{l}712 \\
(64)\end{array}$ & 1089 & $\begin{array}{l}585 \\
(30)\end{array}$ & $\begin{array}{l}662 \\
(64)\end{array}$ & .815 \\
\hline SIZE 4 & $\begin{array}{l}314 \\
(43)\end{array}$ & $\begin{array}{l}424 \\
(62)\end{array}$ & 4232 & $\begin{array}{r}1.560 \\
(43)\end{array}$ & $\begin{array}{r}2211 \\
(62)\end{array}$ & 1861 & $\begin{array}{l}193 \\
(43)\end{array}$ & $\begin{array}{l}.191 \\
(62)\end{array}$ & -.032 & $\begin{array}{l}166 \\
(43)\end{array}$ & $\begin{array}{l}.161 \\
(62)\end{array}$ & -.071 \\
\hline Total & $\begin{array}{c}341 \\
(114)\end{array}$ & $\begin{array}{l}433 \\
(279)\end{array}$ & 5149 & $\begin{array}{l}1184 \\
(114)\end{array}$ & $\begin{array}{l}1393 \\
(279)\end{array}$ & 1244 & $\begin{array}{l}.374 \\
(114)\end{array}$ & $\begin{array}{r}486 \\
(279)\end{array}$ & 1985 & $\begin{array}{r}320 \\
(114)\end{array}$ & $\begin{array}{c}422 \\
(279)\end{array}$ & 1.477 \\
\hline
\end{tabular}

NoTE - Firms are ranked by total insurance output (total present value of losses incurred) SIZE $1=$ smallest size group Values are the inefficiency ratio with the number of observations in parentheses Efficiencies are weighted averages for firms in each cell Weights = actual predicted costs or potential profits. Firms that switched their marketing system or for which the marketıng system is unknown are omitted from ths comparison The $t$-tests measure the statistical significance of the inefficiency differences between direct writers and independent-agency firms in each size class for each efficiency measure (cost, standard profit, and alternative profit) We also conducted $t$-tests of the difference between the ratios of cost inefficiency to potentral profits and profit inefficiency to potential profits for firms in each size class using a given distribution system For example, we tested the statistical significance of the difference between the ratio of cost inefficiency to potential profits and the ratio of profit inefficiency to potential profits for direct writers in size class 1 , etc The results indicate statistically significant differences between cost inefficiencies and (both standard and alternative) profit inefficiencies at the 5\% significance level or better for the overall sample and for all size quartiles except quartile 3 
costs. Presenting cost-inefficiency estimates also enables us to compare our results with those of prior frontier cost-efficiency studies in insurance.

Table 2 shows that independent-agency insurers are substantially less cost efficient than insurers using the direct-writing distribution system. The average inefficiency for independent-agency firms is $43.3 \%$, while the average inefficiency for direct writers is only $34.1 \%$, a statistically significant difference of $9.2 \%$ of predicted costs. ${ }^{20}$ This result is consistent with the prior literature on insurance distribution systems (Joskow 1973; Cummins and VanDerhei 1979; Kim et al. 1996). Thus, the finding that independent-agency firms have higher costs is robust to the choice of methodology and functional form. The marked difference in measured cost efficiency between direct writers and independent-agency insurers does not appear to be the result of differences in firm size. Direct writers dominate independent-agency firms in every size class except the smallest (SIZE 1), where there is a limited sample size of only 17 direct writers. ${ }^{21}$

The cost inefficiencies in table 2 are high relative to the costinefficiency estımates presented in prior studies of property-liability insurers (Weiss 1990; Cummins and Weiss 1993) and most prior studies of noninsurance financial institutions (see Berger and Humphrey 1997) but lower than prior cost-inefficiency estimates for life insurers (Gardner and Grace 1993; Yuengert 1993; Cummins and Zi 1996). As demonstrated below, much of this measured cost inefficiency likely reflects variation in product quality even within a group of firms with the same distribution system.

The profit inefficiency estimates are presented in the "Standard Profit Function" and "Alternative Profit Function" panels of table 2. As explained above, the standard profit function takes as exogenous the output prices, whereas the alternative profit function takes output quantities as given. The profit-inefficiency ratio is an estimate of the proportion of potential profits that is lost due to inefficiency.

The profit function controls for differences in expenditures on service quality for which the firm is compensated on the revenue side. Using the cost function alone would tend to measure differences among firms in service quality as inefficiency. That is, costs incurred by insur-

20. Student's $t$-tests for differences between the direct-writer and independent-agency means by size quartile and overall are provided in table 2

21 The finding that direct writers do not appear to be more efficient than independentagency insurers in the smallest size quartile is consistent with Sass and Gisser (1989) They hypothesize that the direct-writıng distribution system is more likely to be successful for larger firms because of the need to generate a sufficient volume of business to support exclusive agents 
ers to provide higher-quality services would be measured as inefficiencies in the cost-function analysis. However, if the product market values these services and compensates insurers with higher revenues, then the higher costs will be offset by the added revenues, allowing the profit function to correct for the mismeasurement of cost inefficiency. Profit inefficiency should include only the "true" inefficiency component of the cost-inefficiency estimates plus any revenue inefficiencies and thus should net out any mismeasured cost inefficiencies that arise from extra expenditures on product quality that are recompensed on the revenue side.

The standard profit function results reveal that independent-agency firms also appear to be less profit efficient on average than direct writers. The average profit inefficiency for independent-agency insurers is $48.6 \%$ and the average inefficiency for direct writers is $37.4 \%$, a difference of $11.2 \%$ of predicted potential profits. Although this overall average difference is statistically significant, its level of significance is considerably lower than that of the overall cost-inefficiency difference in the "Cost Inefficiency/Actual Costs" panel of the table; and none of the measured profit-inefficiency differences by size quartile are statistically significant, in contrast to the significant cost-inefficiency differences in size classes 2,3 , and 4 . We will directly compare profit inefficiency with cost inefficiency below.

The data in table 2 suggest that smaller firms are much less profit efficient than larger firms, with weighted average inefficiencies declining from more than $90 \%$ for size classes 1 and 2 to only about $19 \%$ for class size 4 . There are three likely reasons for these measured profit scale economies. First, there may simply be strong scale economies in terms of insurer revenues. Since there appear to be no substantial cost scale economies or diseconomies within the range of observed insurer sizes, it may simply be the case that selling more insurance at a given set of input and output prices raises revenues more than costs. ${ }^{22}$ Second, there may be a measurement problem in comparing the outputs of large and small firms because larger firms may engage in product sublines that are more service intensive and generate greater revenues. Third, there may be a scale economy bias in the measured profit efficiencies because of the treatment of outputs as completely variable. As we argued above for treating debt and equity capital as fixed netputs, it may take many decades for firms to build up to the size of the largest insurers in terms of insurance output. For this reason, smaller firms may be

22 As discussed by Berger, Hancock, et al (1993), profit efficiency could be overstated in this circumstance if the firm could not sell its full-efficiency level of output without lowering prices 
compared to a frontier that is effectively unattainable. This problem does not occur for cost inefficiency because the cost equation treats all of the output quantities as exogenous.

To determine whether the differing treatment of output between the cost and profit functions is responsible for the profit-efficiency scale effect, we also estimated an alternative profit function that specifies all outputs as fixed. That is, we replace the output prices in the standard profit function with output quantities, yielding an identical specification to the cost function except for the dependent variable. This alternative form also removes the one difference in specification between the cost equation and the profit equation, to be sure that our results are not related to specification.

The alternative profit-inefficiency estimates shown in table 2 are generally comparable although somewhat smaller than the inefficiencies based on the standard profit function. Thus, the finding of very strong profit scale economies is robust and does not appear to be related to the profit-function specification.

A comparison of the profit efficiencies with some commonly used indicators of profitability also suggest that our profit-efficiency measures are reasonably well behaved. The Spearman (rank-order) correlation of profit efficiency with return on equity (ROE) is .22 and with return on assets (ROA) is .08 , and both are statistically significant at the $1 \%$ level. Finally, the average profit inefficiencies in table 2 suggest that insurers tend to lose about $30 \%$ to $50 \%$ of their potential profits to inefficiency. While these inefficiencies may seem high, they are comparable to the profit inefficiencies found for other financial institutions (Berger, Hancock, et al. 1993).

To conduct the simple version of our test of the market-imperfections versus product-quality hypotheses, we compare the magnitudes of the average cost and profit inefficiencies. If most of the measured costinefficiency difference between direct writers and independent-agency insurers remains as a profit-inefficiency difference, then the marketimperfections hypothesis would be supported. In contrast, if most of the measured cost-inefficiency difference is eliminated when profit inefficiency is measured, then the product-quality hypothesis would be supported.

The profit-inefficiency results shown in table 2 are not directly comparable to the cost-inefficiency results shown in the "Cost Inefficiency/ Actual Costs" panel column of table 2 because cost inefficiency is measured in terms of the proportion of actual predicted costs that are wasted due to inefficiency, whereas profit inefficiency is measured in terms of the proportion of potential profits that are lost. To put the cost and profit results in comparable terms, we restate cost inefficiency in terms of potential profits. The restated cost-inefficiency estimates, shown in the "Cost Inefficiency/Potential Profits" panel of table 2, 
represent the proportion of potential profits that are lost due to cost inefficiency. ${ }^{23}$ Thus, for both costs and profits, we compute the ratio of the dollar value of inefficiency (actual costs minus minimum costs, potential profits minus actual profits) to potential profits. The profitinefficiency ratios should include all of the "true" inefficiency included in the cost-inefficiency ratios plus any revenue inefficiencies and should net out any mismeasured cost inefficiencies that arise from extra expenditures on product quality that are recompensed on the revenue side.

The weighted average cost inefficiency for independent-agency insurers is an astounding $139.3 \%$ of potential profits. ${ }^{24}$ Thus, if the cost inefficiencies are to be believed, these firms are losing money on average. The profit inefficiencies, in contrast, are a weighted average of only $48.6 \%$ of potential profits. Similarly, measured cost inefficiencies exceed potential profits and far outstrip profit inefficiency for insurers using the direct-writing distribution system-measured cost inefficiencies consume $118.4 \%$ of potential profits, whereas profit inefficiencies consume only $37.4 \%$. By definition, "true"' cost inefficiencies can be no greater than profit inefficiencies since profit inefficiencies include both cost and revenue inefficiencies. Thus, these findings are consistent with the product-quality hypothesis, that is, the notion that measured cost inefficiencies primarily reflect unobserved differences in product quality that are recompensed on the revenue side, rather than true inefficiency, even among firms using the same insurance distribution system.

In our simple tests of the hypotheses, we compare the difference in measured cost inefficiency between direct writers and independentagency insurers with the profit-inefficiency difference between the two groups. Independent-agency firms appear both more cost inefficient and more profit inefficient than direct-writing insurers, but the measured cost-inefficiency difference is much larger. The cost-mefficiency difference is $20.9 \%$ of potential profits $(139.3 \%-118.4 \%)$, whereas the profit-inefficiency difference between the groups based on the standard profit function is only $11.2 \%$ of potential profits $(48.6 \%-37.4 \%)$, about one-half as large. The discrepancy is even larger when the comparison is based on the alternative profit function. The difference between the ratios of cost inefficiency to alternative potential profits (not shown in the table) for independent-agency and direct-writing insurers

23. Potential profits from the standard profit function were used as weights for the restated cost-1nefficiency ratios shown in table 2 The results were similar when potential profits from the alternative profit function were used as weights

24. The differences between the ratios of cost inefficiencies to potential profits and both the standard and alternative profit-inefficiency ratios are statistically significant at the 5\% level or better for the entıre sample and for each sıze quartile except quartıle 3 Test results are avalable from the authors 
is $28.8 \%$, whereas the difference in alternative profit inefficiency is only $10.2 \%$. Thus, on the basis of both profit-function specifications, about half or more of the cost-inefficiency difference between the groups does not carry through as profit inefficiency. These results are consistent with the product-quality hypothesis: much of the measured cost inefficiency is not true inefficiency but rather the costs of providing better service.

The difference between the cost-inefficiency-to-potential-profits ratios for direct writers and independent-agency insurers is not statistically significant for the overall sample (it is significant for size classes 2 and 4), although it is much larger than the profit-inefficiency-ratio difference and is statistically significant when predicted costs are used as the denominator. As shown next, however, the cost-inefficiency-topotential-profits difference is statistically significant in the sophisticated-hypothesis tests, which use regression analysis to control for other firm characteristics affecting inefficiency.

\section{Sophisticated Hypothesis Tests Conditioning on Firm Characteristics}

The sophisticated tests of the market-imperfections and product-quality hypotheses control for firm characteristics besides distribution systems that may be affecting the measured inefficiencies of direct-writing and independent-agency insurers. For example, if organizational form (stock versus mutual ownership structure) affects the efficiency of insurers and if the distribution system is statistically related to organizational form, then the average differences in measured inefficiency between direct-writing and independent-agency insurers could be the result of organizational form rather than distribution system. Table 1 shows that independent-agency firms are much more often organized as stock companies than are direct writers, so part of the measured difference in efficiency between the two groups could reflect an underlying difference in efficiency between stock and mutual forms of organization. ${ }^{25}$ Differences in business mix and scale could have similarly confounding effects. As discussed above, it is difficult to change outputs by substantial amounts except over a period of decades.

Accordingly, we regress the cost- and profit-inefficiency ratios from table 2 on a dummy variable for whether the firm is a direct writer (independent agency is the omitted category) and also include controls for organizational form, product mix, and scale to see if the effect of

25. It would not be appropnate to control for such characteristics directly in the cost or profit functions because there may be real efficiency differences between firms with different organizational forms that would be incorrectly removed if organizational form variables were included in the cost or profit functions 
being a direct writer on efficiency is altered by these other variables. The sophisticated tests provide our best evidence on the product-quality and market-imperfections hypotheses because they control for important factors besides distribution systems that may affect efficiency.

The cost-inefficiency regressions are presented in table $3 .{ }^{26}$ The dependent variable in these regressions is the ratio of the measured cost inefficiency to potential profits. Five versions of the regression model are presented, with different combinations of the control variables. Model 1 includes dummy variables for distribution system, organizational form, and size class. The variable DIRECT gives the effect of being a direct writer as opposed to the base case of being an independent-agency firm, STOCK gives the effect of being a stock firm as opposed to the base case of being a mutual organization, and SIZE 2, SIZE 3, and SIZE 4 give the effects of being in the largest three size classes as opposed to the base case of being in the smallest size class. As shown, the coefficient of DIRECT is -0.367 , implying that direct writers are a predicted $36.7 \%$ more cost efficient than independentagency firms of the same organizational form and size class. This finding reinforces the results presented in table 2 and suggests an even larger cost-inefficiency difference between insurers using the two types of distribution systems after controlling for other factors. The other coefficients in model 1 suggest that organizational form is not important for determining the proportıon of potential profits lost to cost inefficiency and that larger firms are less cost efficient.

Model 2 adds control variables for product mix, defined as the ratios of insurance output by category to total insurance output. Three output proportions are included: long-tail personal lines and long- and shorttail commercial lines. The long-tail commercial lines proportion is the omitted category. Inclusion of these variables (along with all the controls for organizational form and scale variables) accounts for the possibility that some firms may be stuck with suboptimal product mix for historical or regulatory reasons, at least over the sample period. The regression results show that the coefficient of DIRECT becomes slightly larger in absolute value, -0.457 , and is again statistically significant, further supporting the robustness of our result that direct writers maintain a measured cost advantage over independent-agency insurers.

Models 3, 4, and 5 test the cost-efficiency effect of distribution systems using interaction terms. ${ }^{27} \mathrm{We}$ interact DIRECT and STOCK with

26. Fifteen of the firms analyzed in table 2 were omitted from the regressions because of missing information on organizational form Omitting these firms in calculating the averages in table 2 had no material effect on the results

27 We deliberately did not include interaction terms in models 1 and 2 to test whether the results are robust to the inclusion or exclusion of interactions Models 1 and 2 thus 
a measure of insurer size, LN(INS OUT), the natural log of total insurance output (discounted real losses for the four lines of insurance). The purpose of switching to the continuous measure of scale instead of the three dummies used in models 1 and 2 is to conserve on the number of interaction terms. These interaction terms allow the effects of distribution system and organizational form to differ by insurer size. In order to determine the effect of distribution system from these equations, that is, the effect on the dependent variable of DIRECT, we take the derivative with respect to DIRECT at the mean value of LN(INS OUT). That is, we evaluate $\partial \mathrm{CI} / \partial \mathrm{DIRECT}=\beta+\gamma \mathrm{LN}$ (INS OUT) at the mean of the data, where $C I$ is the cost inefficiency ratio and $\beta$ and $\gamma$ are the coefficients of DIRECT and LN(INS OUT).DIRECT, respectively. We similarly compute derivatives with respect to the STOCK form of ownership. The values of these derivatives are shown in the bottom rows of the table. ${ }^{28}$

In model 3, we include DIRECT, STOCK, the scale variable LN(INS OUT), and the interactions of the scale variable with the other two variables. In model 4 , we add the controls for product mix. In model 5 , we also add back in the dummy variables for size class to allow for an extra noncontınuous effect of size. The derivatives with respect to DIRECT shown in the bottom row of the table continue to confirm the results of the first two models, indicating that direct writers have a statistically significant measured cost advantage of $34 \%$ or more over independent-agency insurers in terms of potential profits. ${ }^{29}$

Table 4 shows the same five regression equations as table 3 , the only difference being that the dependent variable is the ratio of profit inefficiency to potential profits. ${ }^{30}$ The derivatives with respect to

provide a bridge between the simple means tests presented in table 2 and the more complicated regression specifications, models 3,4 , and 5 .

28 Note that whenever we include LN(INS OUT) in the interaction terms, we also include its level to be an extra control variable and also to be sure that the interactions are not pickıng up the independent effect of size

29 We also conducted regressions that included interaction terms between the organızational form and distribution-system dummy variables (e g, DIRECT STOCK) and interactions between these categorical interaction variables and other variables such as firm size (e g, DIRECT STOCK LN[INS OUT]) The results, avallable from the authors, are qualitatively simılar to those presented in tables 3 and 4 The only noteworthy difference occurred in the most fully specified cost-inefficiency models (analogous to models $3-5$ in table 3), where there is no significant difference in inefficiency between direct-writing and independent-agency stock insurers, whereas the efficiency advantage of direct-writer mutuals over independent-agency mutuals is statistically significant and ranges from $32.8 \%$ to $469 \%$ A possible explanation for this finding is the Kim et al (1996) hypothesis that the independent-agency system helps to control owner-policyholder conflicts in the stock form of ownership, leading to lower agency costs that may offset the cost-efficiency advantage of the direct-writing distribution system.

30 Again, potential profits are based on the standard profit function so that the denominator of the dependent variable is the same as in table 3 . Regressions based on potential profits from the alternative profit function yielded similar results 
TABLE 3 Regressions of Cost Inefficiency on Firm Characteristics

\begin{tabular}{|c|c|c|c|c|c|c|c|c|c|c|}
\hline \multirow[b]{2}{*}{ Varıable } & \multicolumn{2}{|c|}{ Model 1} & \multicolumn{2}{|c|}{ Model 2} & \multicolumn{2}{|c|}{ Model 3} & \multicolumn{2}{|c|}{ Model 4} & \multicolumn{2}{|c|}{ Model 5} \\
\hline & Coefficient & $t$-Rat1o & Coefficient & $t$-Ratio & Coefficient & $t$-Ratio & Coefficient & $t$-Ratio & Coefficient & $t$-Ratio \\
\hline INTERCEPT & 145 & 1451 & 592 & 3540 & -6.358 & -9461 & -6200 & -8600 & -4733 & -4192 \\
\hline DIRECT & -.367 & -3459 & -.457 & -4053 & 2.228 & 2544 & 1830 & 1.961 & 2322 & 2.541 \\
\hline STOCK & .050 & 526 & 011 & 103 & .611 & 782 & 727 & 890 & 1.186 & 1446 \\
\hline LONG-TAIL PERSONAL & & & -529 & -2430 & & & -.229 & -998 & -.321 & -1452 \\
\hline SHORT-TAIL COMMERCIAL & & & -558 & -2788 & & & -166 & -805 & -.364 & -1829 \\
\hline SHORT-TAIL PERSONAL & & & -492 & -1844 & & & -368 & -1320 & -363 & -1.361 \\
\hline SIZE 2 & 140 & 1083 & 123 & 939 & & & & & -317 & -2.034 \\
\hline SIZE 3 & 570 & 4.330 & .535 & 3982 & & & & & -289 & -1352 \\
\hline SIZE 4 & 1.998 & 15155 & 2.009 & 14731 & & & & & 564 & 1.702 \\
\hline LN(INS OUT) & & & & & 440 & 10467 & 442 & 10215 & .358 & 4.757 \\
\hline LN(INS OUT) DIRECT & & & & & -156 & -2988 & -135 & -2457 & -.166 & -3081 \\
\hline LN(INS OUT) STOCK & & & & & -039 & -083 & -047 & -961 & -075 & -1511 \\
\hline Adj. $R^{2}$ & & & & & & & & & & \\
\hline Number of Observations & & & 37 & & & & & & & \\
\hline 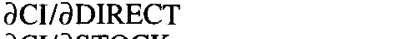 & -367 & -3459 & -457 & -4053 & -347 & -3097 & -396 & -3.470 & -411 & -3614 \\
\hline$\partial \mathrm{CI} / \partial \mathrm{STOCK}$ & 050 & .526 & 011 & 103 & -041 & -418 & -.053 & -.500 & -045 & -.448 \\
\hline
\end{tabular}

Note - Dependent vanable $=\mathrm{Cl}=$ dollar value of cost inefficiency/potential profits The mean of LN(INS OUT) $=$ the mean of the natural log of insurance output $=$ 16503 (to calculate the derivative of the inefficiency ratio with respect to the direct-writer dummy variable in models 3,4 , and 5) The derivative with respect to DIRECT is (the coefficient of DIRECT) + (for models 3,4 , and 5) [the coefficient of LN(INS OUT) DIRECT] [the mean of LN(INS OUT)] 
TABLE 4 Regressions of Profit Inefficiency on Firm Characteristics

\begin{tabular}{|c|c|c|c|c|c|c|c|c|c|c|}
\hline \multirow[b]{2}{*}{ Variable } & \multicolumn{2}{|c|}{ Model 1} & \multicolumn{2}{|c|}{ Model 2} & \multicolumn{2}{|c|}{ Model 3} & \multicolumn{2}{|c|}{ Model 4} & \multicolumn{2}{|c|}{ Model 5} \\
\hline & Coefficient & $t$-Ratıo & Coefficient & $t$-Ratıo & Coefficient & $t$-Ratio & Coefficient & $t$-Ratio & Coefficient & $t$-Rat1o \\
\hline INTERCEPT & 1.032 & 4563 & 988 & 2583 & 2782 & 1961 & 2787 & 1847 & 2.479 & 10472 \\
\hline DIRECT & -.033 & -1383 & -020 & -.792 & 171 & 923 & 258 & 1318 & .155 & 807 \\
\hline STOCK & -048 & -2261 & -039 & -1664 & 188 & 1142 & 239 & 1.399 & .139 & .808 \\
\hline LONG-TAIL PERSONAL & & & 069 & 1394 & & & .072 & 1500 & 083 & 1.795 \\
\hline SHORT-TAIL COMMERCIAL & & & 027 & .587 & & & -069 & -1.599 & -027 & -651 \\
\hline SHORT-TAIL PERSONAL & & & 071 & 1163 & & & 016 & 268 & 017 & .296 \\
\hline SIZE 2 & -055 & -1872 & -.060 & -2012 & & & & & 094 & 2868 \\
\hline SIZE 3 & -266 & -8921 & -270 & -8.781 & & & & & 042 & 945 \\
\hline SIZE 4 & -686 & -2301 & -697 & -22.36 & & & & & -106 & -1519 \\
\hline LN(INS OUT) & & & & & -.122 & -1371 & -123 & -13616 & -106 & -6701 \\
\hline LN(INS OUT) DIRECT & & & & & -012 & -1117 & -017 & -1447 & -010 & -911 \\
\hline LN(INS OUT) STOCK & \multirow{2}{*}{\multicolumn{2}{|c|}{657}} & \multirow{2}{*}{\multicolumn{2}{|c|}{658}} & -.014 & -1.348 & -016 & -1.508 & -010 & -941 \\
\hline Adj $R^{2}$ & & & & & \multirow{2}{*}{\multicolumn{2}{|c|}{$\begin{array}{l}700 \\
378\end{array}$}} & \multirow{2}{*}{\multicolumn{2}{|c|}{705}} & \multicolumn{2}{|c|}{731} \\
\hline Number of Observations & \multicolumn{2}{|c|}{378} & \multicolumn{2}{|c|}{378} & & 378 & & & \multicolumn{2}{|c|}{378} \\
\hline$\partial \mathrm{PI} / \partial \mathrm{DIRECT}$ & -033 & -1383 & -020 & -792 & -033 & -1193 & -017 & -732 & -015 & -.581 \\
\hline$\partial \mathrm{PI} / \partial \mathrm{STOCK}$ & -048 & -2261 & -039 & -1.664 & -035 & -1517 & -017 & -642 & -.022 & -923 \\
\hline
\end{tabular}

NotE -Dependent variable $=$ PI $=$ dollar value of profit inefficiency/potential profits The mean of LN(INS OUT $)=$ the mean of the natural log of insurance output $=$ 16503 (to calculate the derivative of the inefficiency ratio with respect to the direct-writer dummy vanable in models 3,4 , and 5 ) The derivative with respect to DIRECT is (the coefficient of DIRECT) + (for models 3,4, and 5) [the coefficient of LN(INS OUT) DIRECT] [the mean of LN(INS OUT)] This table 1s based on profit inefficiency estimates from the standard profit function Regressions using profit inefficiencies from the alternative profit function yielded simılar results 
DIRECT in table 4 range between -1.5 and -3.3 percentage points of potential profits, suggesting that direct writers may be only slightly more profit efficient than independent-agency firms, considerably smaller than the 11.2 percentage point difference shown in table 2 . Moreover, none of the derivatives of DIRECT in table 4 is significantly different from zero. ${ }^{31}$

The results provide much stronger support for the product-quality hypothesis than for the market-imperfections hypothesis. That is, the differences in measured cost mefficiency shown in table 3 appear to reflect unmeasured differences in product quality (service intensity), which are recompensed by additional revenues, so that there are no statistically significant differences in profit inefficiency between direct writers and independent-agency firms on the basis of table 4 .

\section{Conclusion}

This article addresses the economic puzzle of why alternative distribution systems with significantly different costs are able to coexist by providing frontier cost- and profit-efficiency estimates for the propertyliability insurance industry. This industry provides an ideal laboratory for testing alternative hypotheses about the coexistence of distribution systems with different costs because the independent-agency system is known to have higher costs for distributing virtually the same insurance contracts as the direct-writing system. We test the marketimperfections hypothesis, under which impediments to competition allow independent-agency insurers to be less efficient, against the product-quality hypotheis, under which independent-agency insurers incur higher costs providing more or better services for which they are recompensed with higher revenues.

Our methodology for resolving this controversy involves comparing

31. We also conducted two additional robustness checks (1) To check to see if differences in portfolio composition across insurers might be affecting the results, we modified our cross-sectional regressions by adding three portfolio composition variables (the proportions of each insurer's portfolio invested in stocks, bonds, and short-term debt instruments - the three most important investment categories for property-liability insurers). The portfolio composition variables were not statistically significant in the cost-inefficiency regressions (analogous to table 3 ) and had no material effect on the cost-inefficiency differences or significance tests between direct writers and independent-agency firms The portfolio variables were statıstically significant in the profit-inefficiency regressions (analogous to table 4) but had no material effect on the distribution-system inefficiency differences or significance tests. Thus, we do not believe that differences in portfolio composition are affecting the conclusions drawn from our analysis (2) We reestimated our models omitting from the sample the largest and smallest $10 \%$ of firms in terms of total insurance output The conclusions are the same there is a statistically significant difference in cost inefficiency but no significant difference in profit inefficiency between direct-writing and independent-agency insurers The results based on the averages (analogous to table 2) also support similar conclusions after omitting firms in the largest and smallest size deciles 
the frontier cost and profit inefficiencies of insurers employing the alternative distribution systems. In our simple tests, we compare the average cost and profit inefficiencies of direct-writing and independentagency firms. Under the product-quality hypothesis, higher measured cost inefficiencies for independent-agency firms represent higherquality services that are rewarded by the market with higher revenues, so that the profit-inefficiency differences between the two distribution systems should be much smaller on average than the measured cost-inefficiency differences. In contrast, under the market-imperfections hypothesis, most of the measured cost-inefficiency differences reflect "true" differences in inefficiency between the two systems that should also be measured as profit-inefficiency differences. In our sophisticated tests, the average inefficiency differences are measured after conditioning on factors that may not be fully under the control of insurers in the short run. These tests are based on regressions in which organizational form, business mix, and scale are included as controls.

Our empirical results confirm that independent-agency firms are less cost efficient on average than direct writers. The principal finding of the study is that most of the average cost-efficiency difference between the two groups of firms does not carry through as a profit-efficiency difference. This is a robust result that holds both in our simple tests of average efficiency and in our sophisticated tests using regression analysis. On the basis of averages, the profit-inefficiency difference is about one-half, or less, as large as the cost-inefficiency difference. On the basis of the regression analysis, the profit-inefficiency differences are about one-tenth as large as the cost-inefficiency differences, and the profit-inefficiency differences are not statistically significant. We prefer the more sophisticated regression analysis, which suggests that independent-agency firms are predicted to generate almost the same profitability for delivering the same mix and quantity of outputs under the same organizational form. The results thus provide much stronger support for the product-quality hypothesis than for the market-imperfections hypothesis. The higher costs of independent-agency firms appear to be due primarily to the provision of higher-quality services, which are compensated for by additional revenues.

These findings have potentially important implications for efficiency studies in other industries. They suggest that relying on cost efficiency alone may produce misleading results, unless appropriate controls are available for product quality. Such controls often are not available, especially in the services sector where outputs are often intangible and implicitly priced. The estımation of profit efficiency may be necessary to mitigate this problem and yield more meaningful efficiency estimates.

A significant public policy implication is that regulatory decisions perhaps should not be based on costs alone. Our findings imply that 
cost differences among insurers are mostly attributable to service differences rather than to inefficiency and therefore do not represent social costs. Thus, using regulatory rate suppression as a policy mechanism to reduce marketing costs, as proposed in some states, may deprive some market segments of desired services and adversely affect economic welfare.

\section{References}

Akhavein, J D , Berger, A. N , and Humphrey, D B 1997 The effects of megamergers on efficiency and prices Evidence from a bank profit function Review of Industrial Organization 12 (February) 95-139.

Akhavein, J D, Swamy, P. A. V B, Taubman, S B, and Singamsettı, R N 1997. A general method of deriving the efficiencies of banks from a profit function. Journal of Productivity Analysis 8 (March) 71-93

A M. Best Co. various years. Best's Aggregates and Averages. Oldwick, N.J A M. Best

Badrinath, S. G, Kale, J R., and Ryan, H E, Jr. 1996 Characteristıcs of common stock holdings of insurance companies. Journal of Risk and Insurance 63 (March) 49-76

Berger, A. N. 1993 "Distribution-free" estimates of efficiency in the U.S banking industry and tests of the standard distributional assumptions. Journal of Productivity Analysts 4 (September) $261-92$

Berger, A N, Hancock, D; and Humphrey, D B 1993. Bank efficiency derived from the profit function. Journal of Banking and Finance 17 (April) 317-47

Berger, A N, and Humphrey, D B. 1991 The dominance of inefficiencies over scale and product mix economies in banking Journal of Monetary Economics 28 (August) 117 48

Berger, A N, and Humphrey, D B 1992 Measurement and efficiency issues in commercial bankıng In Z Griliches (ed ), Output Measurement in the Service Sectors National Bureau of Economic Research, Studies in Income and Wealth, vol 56. Chicago University of Chicago Press 245-79

Berger, A N , and Humphrey, D B 1997 Efficiency of financial institutions International survey and directions for future research. European Journal of Operational Research 98 (April) 175-212

Berger, A N., Hunter, W C, and Timme, S. G 1993 The efficiency of financial institutions A review and preview of research past, present, and future Journal of Banking and Finance 17 (April) 221-49

Berger, A N.; Leusner, J H, and Mingo, J J 1997, in press The efficiency of bank branches Journal of Monetary Economics 40 (August)

Berger, L A., Kleındorfer, P R, and Kunreuther, H. 1989 A dynamic model of the transmission of price information in auto insurance markets Journal of Risk and Insurance 56 (March) 17-33

Braeutıgam, R R, and Pauly, M V 1986 Cost function estımation and quality bias The regulated automobile insurance industry Rand Joumal of Economics 17 (Winter) 60617

Bughin, J 1993. X-inefficiency in the insurance industry An analysis of the cost effectiveness of the investment function of U.S companies Workıng paper Brussels. Universite Libre de Bruxelles

Coleman, T, Fisher, L.; and Ibbotson, R. 1989 US Treasury yield curves 1926-1988 New York Moody's Investors Service

Cummins, J. D, and VanDerhe1, J L 1979 The relative efficiency of property-liability distribution systems Bell Journal of Economics 10 (Autumn) 709-19

Cummins, J D., and Weiss, M A 1993 Measuring cost efficiency in the property-liability insurance industry Journal of Banking and Finance 17 (April): 463-82

Cummıns, J D , and Z1, H In press Comparison of frontier efficiency methods. An application to the U S life insurance industry Journal of Productivity Analysis 
Dahlby, B , and West, D S 1986 Price dispersion in an automobile insurance market Journal of Political Economy 94 (Aprl) 418-38.

Fama, E 1985. What's different about banks? Journal of Monetary Economics 15 (January): $29-39$

Fecher, F ; Kessler, D, Perelman, S, and Pestieau, P 1993. Productive performance in the French insurance industry Journal of Productivity Analysis 4 (June) 77-93

Gardner, L. A , and Grace, M. F 1993. X-efficiency in the U.S. life insurance industry. Journal of Banking and Finance 17 (April). 497-510.

Humphrey, D B, and Pulley, L B 1997 Banks' responses to deregulation. Profits, technology, and efficiency Journal of Money, Credit, and Banking 29 (February). 73-93

Joskow, P 1973 Cartels, competition, and regulation in the property-liability insurance industry Bell Journal of Economics and Management Science 4 (Autumn) 395-427

Kım, W J , Mayers, D ; and Smith, C W., Jr. 1996. On the choice of insurance distribution systems Journal of Rusk and Insurance 62 (June) 207-28

Kraus, A., and Ross, S A 1982 The determınation of farr profits for the property-liability insurance firm. Journal of Finance 37 (September) 1015-28

Mayers, D, and Smith, C. W, Jr 1981 Contractual provisions, organizational structure, and conflict control in insurance markets Journal of Business 54 (July): 407-34

McAllister, P, and McManus, D 1993 Resolving the scale efficiency puzzle in banking Journal of Banking and Finance 17 (April), 389-405.

Mitchell, K, and Onvural, N M 1996 Economres of scale and scope at large commercial banks Evidence from the Founer flexible functional form. Joumal of Money, Credit, and Banking 28 (May) 178-99.

Pauly, M V , Kunreuther, H , and Kleındorfer, P R 1986 Regulation and quality competıtion in the U S insurance industry. In J Finsinger and M Pauly (eds ). The Economics of Insurance Regulation New York St. Martın's Press.

Regan, L, and Tennyson, S 1996 Agent discretion and the choice of insurance marketıng system Journal of Law and Economics 39 (October) 637-66

Sass, T., and Gisser, M 1989 Agency costs, firm size, and exclusive dealıng Journal of Law and Economics 32 (October) $381-400$

Schmidt, P, and Sickles, R C 1984. Production frontiers and panel data Journal of Bustness and Economic Statistics 2 (October) 367-74

We1ss, M A 1990 Productivity growth and regulation of $\mathrm{p} / 1$ insurance 1980-1984. Journal of Productivity Analysis 2 (December) 15-38

Winter, R 1994 The dynamics of competitive insurance markets. Journal of Financial Intermediation 3 379-415

Yuengert, A M 1993 The measurement of efficiency in life insurance Estimates of a mixed normal-gamma error model Journal of Banking and Finance 17 (April) 48396 